\title{
Density and Ultrasonic Characterization of Oil Palm Trunk Infected by Ganoderma Boninense Disease
}

\author{
M. M. K. Najmie, K. Khalid, A. A Sidek and M. A. Jusoh \\ Department of Physics, Faculty of Science, Universiti Putra Malaysia, 43400 Serdang Selangor, Malaysia, \\ mknajmie@gmail.com
}

\begin{abstract}
Oil palm trunks infected by Ganoderma boninense disease have been studied using density and ultrasonic characterizations. The ultrasonic characterizations have been performed using a commercial ultrasonic instrument at the frequency of $54 \mathrm{kHz}$. The measurements have been done in 3 zones: inner zone, central zone and peripheral zone. It was found that the stem density of the oil palm infected by Ganoderma boninense disease was reduced by $50 \%$ in comparison to the original healthy trunk. From this effect the velocity of the ultrasonic wave propagated through the Longitudinal, Radial, and Tangential directions is lower for the trunk infected by Ganoderma boninense disease compared to a healthy trunk. For the $10 \mathrm{~cm}$ thickness of samples, the ultrasonic velocity for all transit directions was in range of $260-750 \mathrm{~ms}^{-1}$ for the infected sample, whereas for healthy samples was in the range of $460-900 \mathrm{~ms}^{-1}$. These results are very useful for the detection of the area which has been affected by the disease.
\end{abstract}

Keywords: Oil palm trunk, ultrasonic testing, elasticity constant, Ganoderma boninense

\section{INTRODUCTION}

$\mathrm{T}_{\mathrm{s}}$ HE OIL PALM TREE Elaeis guineensis, which belongs to the Palma family, is one of the most versatile crops in tropical countries. Oil palm was the major commodity inside the Malaysian agriculture sector. Commercial cultivation of the oil palm started in 1917 and has expanded tremendously in recent years because it is suitable to be planted in most lands in Malaysia. Malaysia is presently the world's leading exporter of oil palm having a $60 \%$ market share and oil palm was second only to soybean as the major source of vegetable oil. It has spread throughout the tropics and is now grown in 16 or more countries. However, the major center of production is in South East Asia (SEA) with Malaysia and Indonesia together accounting for around $83 \%$ of world oil palm production in 2001 [1]. The oil palm exportation reached about RM31 billion increased by $8.54 \%$ or RM2.44 billion in 2006 compared to 2005 [2]. Oil palm trunk can also be used to make furniture, as an additive in concrete, laminated oil palm veneer lumber and raw material for activated carbon. However, a soil fungus pathogen, Ganoderma boninense, which causes basal stem rot in oil palms trunk, ruins thousands of hectares of plantations in Southeast Asia every year. The disease causes infected palm trunks to fracture at the base, thus causing direct loss of oil palm trees.

The Ganoderma problems had been known for decades, but the search for solution was considerably hampered by a natural constraint. The disease does not cause external symptoms until it is too far advanced and at a stage when trees cannot respond to treatment anymore, as shown in Fig.1(a). Primary infection of palms by Ganoderma species has been considered to occur by contact of living palm roots with colonized debris within the soil [3]. Secondary spread of inoculums has been assumed to be by contact of living palm roots with each other [4]. Beside the very old palms, palms between 7 to 15 years old are also infected. This is the prime age of fruit production and effort should be made to curb disease spread and loss of trees especially from this age group. Because the external symptoms become visible when the disease is too far advanced, very little information of the fungus, especially during its earliest point of entry, is known. So Ganoderma boninense disease is like a silent time bomb to oil palm trees.

Attempts to control this disease in the fields with fungicide have been made by various workers, but the results are inconclusive, though some systematic fungicides seem to be promising. The methods of fungicide application include soil drenching, trunk injection, or combination of these two methods [5]. However, management of chemical and biological control would be more effective if the disease could be detected before its external symptoms become evident. Ultrasonic testing is one of the non-destructive testing (NDT) methods which offer advantages due to the possibility of evaluating the structural integrity of an element without extracting test specimens, faster analysis of large populations, and versatility to adapt to standardized production line routines.

Another application of the non-destructive methods is the evaluation of structures that are in use, i.e., in situ evaluation, allowing for their maintenance or rehabilitation through a mapping of the deteriorated areas, which permits evaluations to be made of their structural integrity without the need to remove part of the structure [6]. Until now there was still no conclusive method for early detection of basal stem rot in order to stop the disease from spreading. The disease has now reached an alarming state as more and more palms become infected, and the target hosts are starting to shift towards even younger palms.

The objective of the present work is to study the ultrasonic transmission properties of the oil palm trunks through the healthy tissue and tissue infected by Ganoderma boninense. 


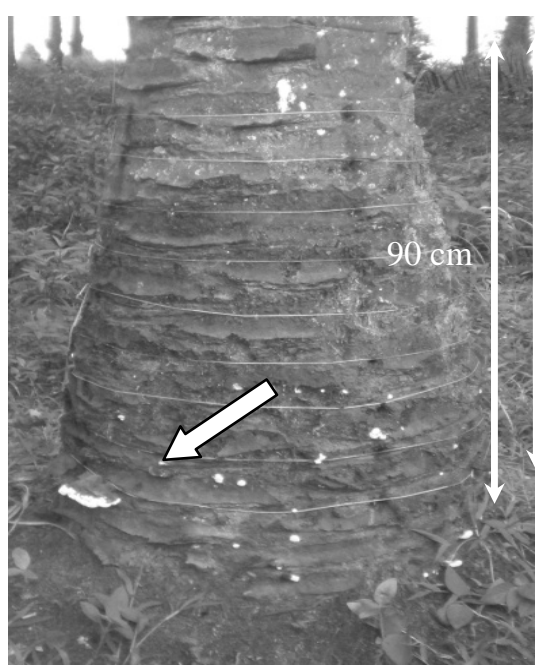

(a)

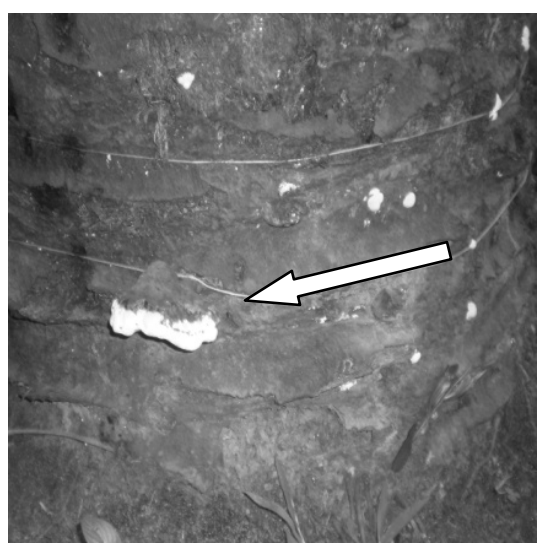

(b)

Fig.1. (a) Oil palm tree infected by Ganoderma boninese disease. (b) A mature Ganoderma fructification at oil palm trunk.

\section{SUBJECT \& METHODS}

An oil palm tree was infected by Ganoderma boninense disease obtained in Oil palm Farm, UPM. That oil palm tree reached the age of 30 years and showed Ganoderma boninense infection with the appearance of a mature Ganoderma fructification at stem. The lower fronds of the oil palm were dead and fractured as shown in Fig.1. Then, the oil palm trunk was cut from $20 \mathrm{~cm}$ above the ground to $100 \mathrm{~cm}$ height using a chainsaw. All samples were cut using Radial Arm Saw found at the Forest Research Institute Malaysia (FRIM). The trunk was cut to blocks of the size measuring $5 \times 10 \times 10 \mathrm{~cm}$ from stem center as shown in Fig. 2. The number of samples suitable to be used in this project was 27 and they were divided into 3 sections, namely: inner zone, central zone and peripheral zone. Then the samples were weighed using analytical balance to know the mass and density. The volumes of samples were also measured using digital veneer caliper. Density is the ratio of mass to volume of the sample with unit $\mathrm{kgm}^{-3}$, and it is written in equation form as:

$$
\rho=m / v ，
$$

where $\rho=$ density of wood, $m=$ mass of wood and $V=$ volume of wood.

As much as 10 readings were adopted for every sample and average value was calculated. Ultrasonic tester V-Meter Mark II with $54 \mathrm{kHz}$ transmitter and receiver transducers typically used for wood measurement, and concrete, were used to measure transit time in three directions: tangential direction, radial direction and longitudinal direction, using direct transmission method based on fiber directions of oil palm trunk as shown in Fig.3.Transit time pulse, $t$ propagate across material collected between two transducers, with known material length, $l$ will give ultrasonic velocity, $v$. Velocity of ultrasonic wave was obtained through following equation and the unit is meter per second, $\mathrm{ms}^{-1}$ :

$$
v=l / t
$$

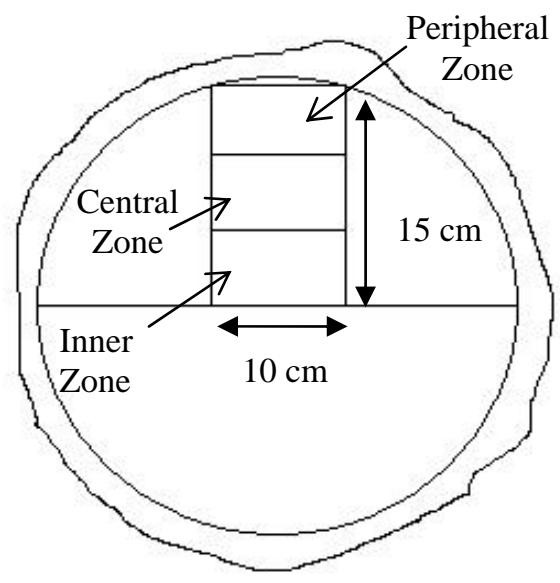

(a)

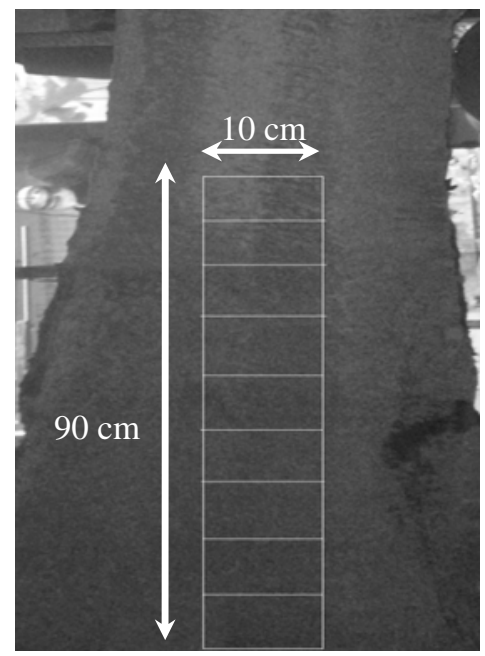

(b)

Fig.2. (a) Cross section of sample for measurement from above. (b) Cross section of sample for measurement after being split in two and divided to 9 parts. 


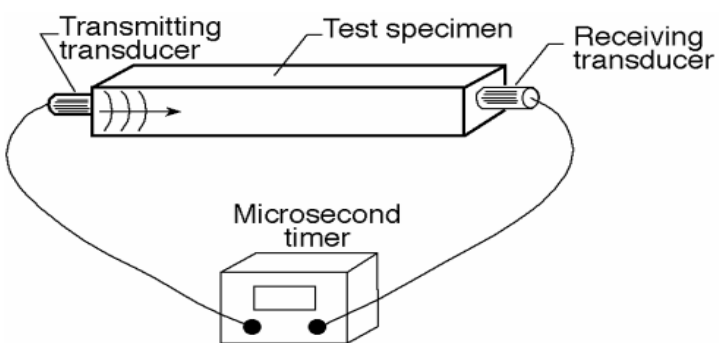

Fig.3. Ultrasonic measurement system used to measure oil palm trunk.

\section{RESULTS AND DISCUSSION}

The relationship between density and height of the oil palm trunk is shown in Fig.4. The graph shows that the density of infected area by Ganoderma boninense disease had lower density value compared to healthy area for every zone. There are discolorations between healthy areas and areas infected by Ganoderma boninense disease. Healthy areas were colored yellow white at parenchyma tissue while areas infected by Ganoderma boninense disease were colored dark brown or blonde at parenchyma tissue. Generally, the dropping of the density in the infected area is about $50 \%$ from the original density. This means that the tree can easily fall down when it arrives at the critical stage. Oil palm wood is from monocotyledon type where distribution of vascular bundle is irregular and disarranged and it has no growth rings, while hardwood and softwood is dicotyledonous where distribution of vascular bundle is arranged and forms a circle spiral and also possesses growth rings. The density at the peripheral region was above the values of the inner region. Across the trunk the density is influenced largely by the number of vascular bundles per square unit which decreases towards the center. The area infected by Ganoderma boninense disease has lower density in comparison to the healthy area and this pattern applies for all directions. These characteristics show that the area infected by Ganoderma boninense disease can reduce the stem stiffness and weaken the building structure of the oil palm tree. It will also cause the oil palm tree to fall down, besides encouraging insect attacks such as ants, termites and tree worms.

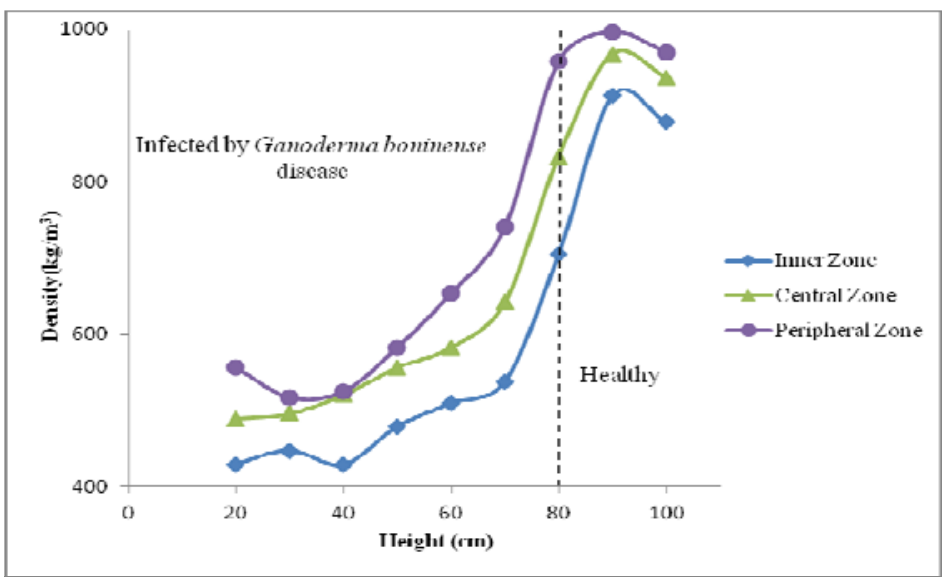

Fig.4. Relationship between density and height of the oil palm trunk.

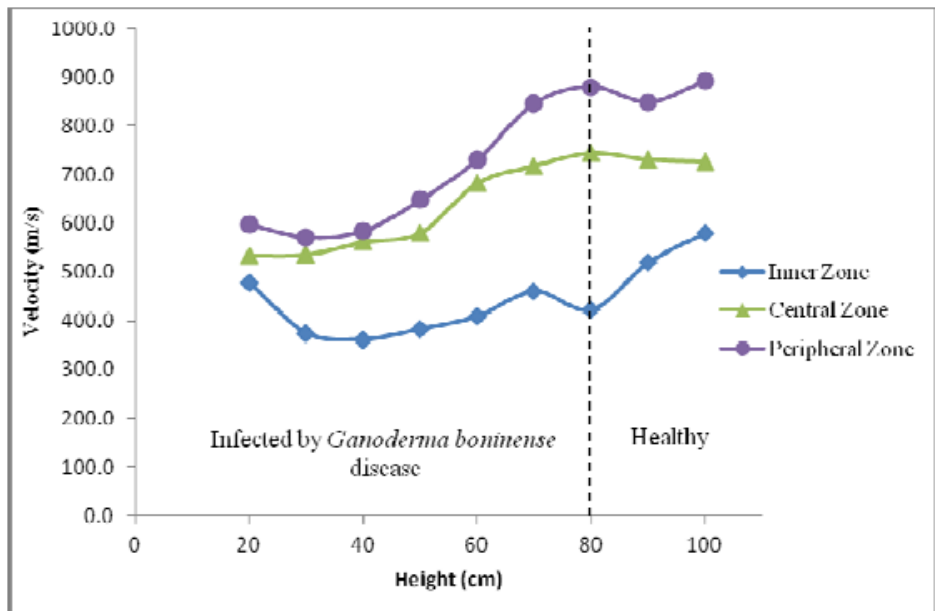

Fig.5. Relationship between ultrasonic velocity for tangential direction and height of the oil palm trunk (cut samples). 
Fig.5 indicates the graph of velocity for tangential direction at different height of oil palm trunk. The graph shows that those areas which are infected by Ganoderma boninense disease have lower velocity in comparison to healthy areas. Peripheral zone has higher velocity and is followed by central zone and inner zone for the same thickness of the samples. In the infected area the average velocity is $423.4 \mathrm{~ms}^{-1}$ at inner zone, $571.1 \mathrm{~ms}^{-1}$ at central zone and $615.5 \mathrm{~ms}^{-1}$ at peripheral zone, while in the healthy area the velocity is $507.5 \mathrm{~ms}^{-1}$ at inner zone followed by $732.6 \mathrm{~ms}^{-1}$ at central zone and peripheral zone, $873.3 \mathrm{~ms}^{-1}$. The graph of velocity in radial direction at different height of oil palm trunk is shown in Fig.6. The results of radial direction follow the same pattern as tangential direction where at inner zone the average velocity of healthy areas is $489.2 \mathrm{~ms}^{-1}$ and average velocity of infected areas is 307.9 $\mathrm{ms}^{-1}$, while at central zone, average velocity of healthy area is $716.9 \mathrm{~ms}^{-1}$ and average velocity of infected area is 548.3 $\mathrm{ms}^{-1}$. Peripheral zone has higher average velocity at healthy areas, $828.8 \mathrm{~ms}^{-1}$ and velocity at infected areas is $657.0 \mathrm{~ms}$ 1. Peripheral zone has a narrow layer of parenchyma and congested vascular bundles that transform into a sclerotic zone, which provides the main mechanical support for the palm trunk.

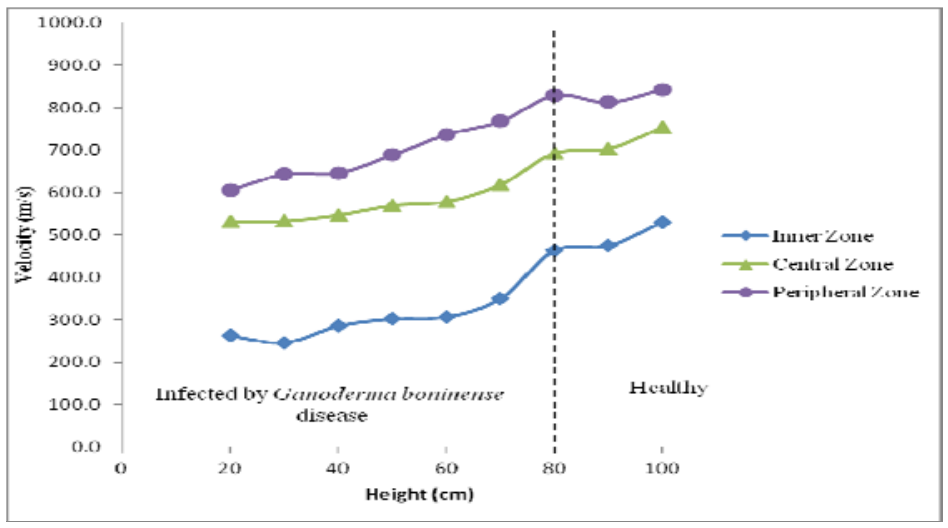

Fig.6. Relationship between ultrasonic velocity for radial direction and height of the oil palm trunk (cut samples).

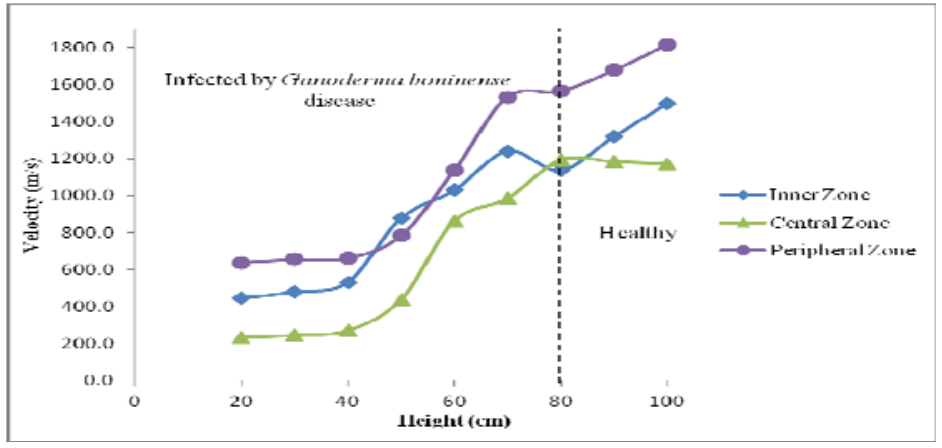

Fig.7. Relationship between ultrasonic velocity for longitudinal direction and height of the oil palm trunk (cut samples).

The velocity for longitudinal direction is the highest average velocity compared to radial direction and tangential direction. This is because ultrasonic wave can propagate faster when mechanical energy is parallel to grain direction. In Fig. 7, the results of average velocity for infected area are almost the same for all zones ranging from 275 to $625 \mathrm{~ms}^{-1}$. But in the healthy area, there is a significant difference in velocity between the zones. The velocity at inner zone is $1138 \mathrm{~ms}^{-1}$, at central zone is $1183.1 \mathrm{~ms}^{-1}$ and peripheral zone is $1565 \mathrm{~ms}^{-1}$.

\section{CONCLUSION}

These results are very useful for the ultrasonic detection of the areas which have been infected by the Ganoderma boninense disease. The Ganoderma boninense disease can reduce up to $50 \%$ of density compared to the original oil palm density. Oil palm trunk fully infected by Ganoderma boninense disease showed mature Ganoderma fructification at stem. Ultrasonic velocity of infected area is lower than healthy area. Peripheral zone has lower ultrasonic velocity compared to central zone and inner zone at tangential direction and radial direction. In longitudinal direction, central zone shows higher transit time reading at infected areas. For future work we propose that the ultrasonic study should cover more oil palm trees that differ in age and maturity. Some parameters such as moisture content, density, fiber dimension, chemical content and mechanical qualities of oil palm trunk have different characteristics with respect to tree age. Follow-up study can also be done on different palm species such as coconut tree for comparative purposes. To overcome the problem of energy loss of ultrasonic wave, especially for big trees or young trees, a high power transducer should be considered. 


\section{ACKNOWLEDGEMENT}

This project is supported by a research grant of Fundamental Research Grant Scheme (FRGS). Vote number: 55232133. The author would like to thank Taman Pertanian Univeristi (TPU), Universiti Putra Malaysia and Forest Research Institute Malaysia (FRIM) for providing access to their facilities.

\section{REFERENCES}

[1] Turner, P.D. (1965). The incidence of Ganoderma disease of oil palms in Malaya and its relation to previous crop. Annals of Applied Biology, 55, 417-23.

[2] Pilotti, C.A., Sanderson, F.R., Aitken, E.A.B., Bridge, P.D. (2000). Genetic variation in Ganoderma spp. from Papua New Guinea as revealed by molecular (PCR) methods. In Flood, J., Bridge, P.D., Holderness, M. (eds.) Ganoderma Diseases of Perennial Crops. Wallingford, UK: CABI Publishing, 195-204.
[3] Idris, A.S., Ismail, S., Arifin, D., Ahmad, H. (2002). Control of Ganoderma Infected Palm - Development of Pressure Injection and Field Applications. MPOB Information Series TT No. 131.

[4] De Oliveira, F.G.R., Candian, M., Lucchette, F.F. (2005). A technical note on the relationship between ultrasonic velocity and moisture content of Brazilian hardwood (Goupia glabra). Building and Environment, 40, 297-300.

[5] Erwinsyah. (2008). Improvement of Oil Palm Wood Properties Using Bioresin. $\mathrm{PhD}$ thesis, Dresden University of Technology, Institute of International Forestry and Forest Products.

[6] Basri, W.M., Akmar, S.N.A., Henson, I.E. (2004). Oil palm - achievements and potential. Proceedings of the 4th International Crop Science Congress, 26 Sep - 1 Oct 2004. Brisbane, Australia.

[7] ISTA Mielke GmbH. (2007). Oil World, Vol. 50, No. 7. Hamburg: ISTA Mielke, www.oilworld.biz.

Received August 3, 2011. Accepted October 21, 2011. 